\section{PS1:4 SEARCHING BIOMARKERS IN LUPUS NEPHRITIS BY PROTEOMICS}

${ }^{1}$ NA Rivera García, ${ }^{1} M E$ Ruiz Lucea, 'E Eduardo Úcar, ${ }^{1} M L$ Garcia Vivar, ${ }^{1}$ OB Fernandez Berrizbeitia, ${ }^{1} \mathrm{E}$ Galindez Agirregoikoa, ${ }^{1} \mathrm{JM}$ Blanco Madrigal, ${ }^{1} \mathrm{I}$ Torre Salaberri, ${ }^{1} \mathrm{CE}$ Perez Velasquez, ${ }^{2} \mathrm{~F}$ Elortza, ${ }^{2} \mathrm{M}$ Azkargorta. ${ }^{1}$ Basurto University Hospital, Bilbao, Spain; ${ }^{2} \mathrm{CiC}$ bioGune, Bilbao, Spain

\subsection{6/lupus-2018-abstract.53}

Introduction Lupus nephropathy (NL) is an important cause of morbidity and mortality in patients with SLE. The objective of the renal biopsy is to determine the type of glomerulonephritis that the patient presents to be treated. A proteomics study is proposed to determine biomarkers that help us to differentiate patients diagnosed with SLE with and without renal involvement.

Objective To determine if there are a different patron of proteins between patients diagnosed with SLE with and without renal involvement.

Methods We selected 12 patients diagnosed with SLE with renal involvement and 14 patients diagnosed with SLE without renal involvement. A 24 hour urine sample was obtained for analysis.

Results A total of 292 proteins (identified with at least two peptides with a FDR $<1 \%$ ) were quantified and further considered in the analysis. The Principal Components Analysis (PCA) reflected the differential presence of 142 proteins $(\mathrm{p}<0.01)$. Of these, 130 were less abundant in the urine of the patients with renal damage, whereas 17 showed the opposite pattern, being more abundant in the patients with affected renal function. Consistent with the nature of the sample, the Gene Ontology (GO analysis) of the whole list of identified proteins revealed the presence of extracellular ( 277 proteins, $p=2.25 \mathrm{E}-$

\section{4 genes}

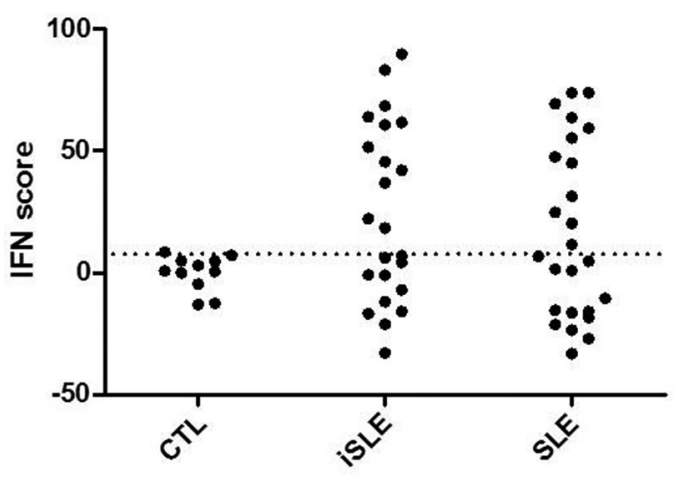

Module 3.4

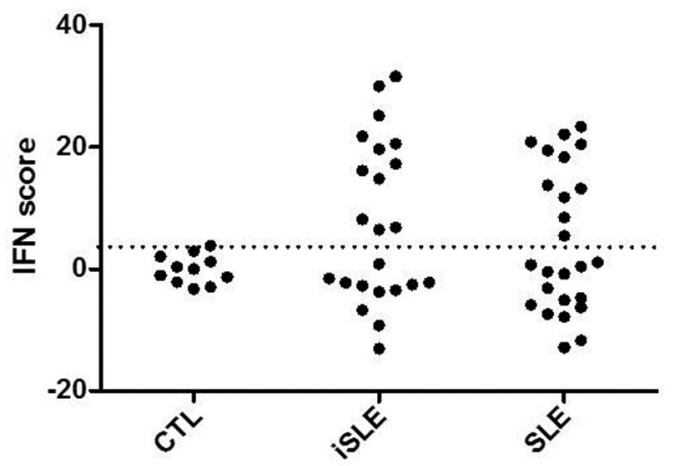

171) and secretion-related proteins (49 proteins, $\mathrm{p}=1.1 \mathrm{E}-09$ ), among others. Proteins related to defensive processes were prominent among them. Interestingly, the subset of proteins whose abundance increases upon renal damage is comprised of typical highly-abundant serum proteins. These proteins render a large number of peptides, suggesting they are very abundant. On the other hand, a large number of proteins became significantly less abundant upon renal damage. The presence of highly abundant serum proteins in the urine of patients with compromised renal function may explain this phenomenon, since this will provoke a dramatic reduction in the relative abundance of the proteins already present in their urine.

Conclusion A different protein pattern is observed between the two groups of patients, so in a more detailed study we can indicate if some of these can serve as prognostic markers for this type of patients.

\section{PS1:5 INTERFERON SIGNATURE IS INCREASED IN INCOMPLETE SLE AND CORRELATES WITH MXA AND IP-10 LEVELS}

W Lambers, J Westra, B Doornbos, MF Jonkman, H Bootsma, K de Leeuw. University Medical Centre Groningen (UMCG), Groningen, The Netherlands

\subsection{6/lupus-2018-abstract.54}

Introduction Most SLE patients have increased expression of type-I interferon (IFN)-regulated genes, the so-called IFN-signature. $^{1}$ IFN-regulated genes are subdivided in 3 modules (M1.2, M3.4 and M5.12). ${ }^{2}$ Module 1.2 is associated with disease presence and the latter two seem to be sequentially activated and to correspond with active disease. ${ }^{3}$

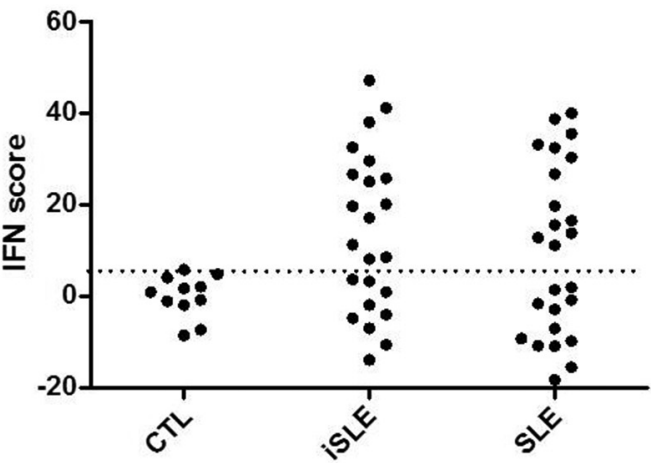

Module 5.12

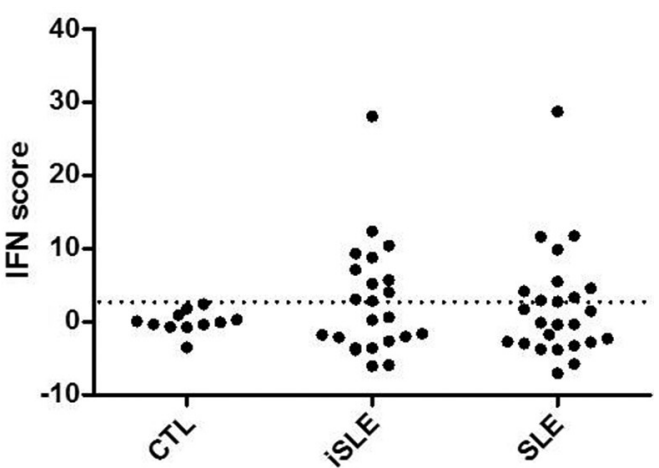

